\title{
Phonological Errors and L1 Interference: A Case Study of Jordanian Learners of English as a Foreign Language
}

\author{
Fatima Al-Shalabi \\ Jordan
}

Received: June 2, 2021

Accepted: July 30, $2021 \quad$ Published: August 1, 2021

doi:10.5296/jse.v11i3.18819

URL: https://doi.org/10.5296/jse.v11i3.18819

\begin{abstract}
This study investigates the phonological errors made by Jordanian learners of English as a foreign language. It aims to explore the role played by the learners' first language in committing such errors. The researcher collected data from 20 Jordanian learners of English; all were in Grade 10 and speak Jordanian Arabic (JA) as their native language. The researcher asked each participant to read a list of words and recorded their pronunciation. The analysis of data showed that participants made two types of errors: insertion errors and substitution errors. The results also revealed that learners' first language interference is the major source of both insertion and substitution errors. The study made some suggestions to eliminate errors and recommendations for future research.
\end{abstract}

Keywords: Jordanian EFL learners, phonological errors, foreign language acquisition, insertion, substitution, declusterisation 


\section{Introduction}

Being fluent in any foreign language requires having a good command over its spoken and written forms. The spoken form involves listening and speaking skills, whereas the written form requires the proper acquisition of reading and writing skills. Learners' first language interference in both forms of the foreign language is inevitable; it makes the process of learning either easy in case of similarities or difficult when many differences exist between the systems of the two languages. To succeed in any situation, speakers must avoid any misunderstanding and miscommunication during a conversation, so their speaking and listening skills should be to some extent perfect. Especially for the former, correct pronunciation is essential. Many studies around the world investigated the EFL learners' interlanguage intending to detect the difficulties they encounter through the identification of the errors they committed and put forward some solutions. Arab learners of English are no exception; they have difficulties in speaking, pronunciation, vocabulary, spelling and writing (Abu Rass, 2015). Therefore, investigating learners' errors is essential in foreign language studies as it may contribute to identifying learners' problematic areas and propose adequate solutions.

Error analysis theory appeared in the late 1960s and early 1970s; it was founded by S. P. Corder. Making errors is viewed as a device that language learners use in learning their first language as well as a second or foreign language. As Corder (1981) put it "It is a way the learner has of testing his hypotheses about the nature of the language he is learning. The making of errors then is a strategy employed both by children acquiring their mother tongue and by those learning a second language" (p.11). Learners' errors are significant to researchers, learners and teachers. Researchers can obtain knowledge about how language is acquired, learners may avoid errors when they are corrected by fluent speakers and teachers can understand which linguistic items have been acquired and which ones have not been which will, in turn, helps them to focus on the difficult areas for their students.

According to Richard (1974), errors can be classified into two types: interlingual and developmental errors. Interlingual errors are those caused by the interference of the learner's native language which can be found at different linguistic levels; phonological, morphological, grammatical or lexical. However, they might be caused by other factors outside the target language such as psychological strategies or the context of communication. On the other hand, developmental errors are caused by the learner's learning strategies while forming hypotheses about the rules of the target language; they are classified under different types such as overgeneralization, incomplete application of rules, and ignorance of rule restriction. As for the present study, it deals with the interlingual errors caused by learners' mother tongue interference at the phonological level.

\section{Literature Review}

Phonological errors have been investigated in several studies. In the Jordanian context, for instance, Al-Saidat (2010) focused his study on the English syllable as produced by Jordanian learners of English in order to find out the types of errors committed in this area and the sources of these errors. The study revealed that the English initial CCC- and final -CCC and -CCCC were problematic for his participants. He attributes such difficulties to the fact that these 
clusters do not exist in the participants' first language for which reason participants inserted a short, $/ \mathrm{I} /$, to ease the pronunciation of the words where these difficulties were encountered producing various pronunciation errors. In the same vein, Al-Shuaibi (2006) investigated the pronunciation of the English syllable-initial and final-consonant clusters as produced by Yemeni speakers. The results showed that the initial and final consonant clusters of the type: $\mathrm{CC}$ and CCC are difficult for Yemeni speakers of English; they insert the short vowels /a/, /I/ and $/ \mathfrak{p} /$ in order to ease the pronunciation of such difficult sequences. The author attributed this to the fact that these structures do not exist in Yemeni Arabic, the participants' first language.

Participants' first language seems to interfere not only in the spoken form of L2 but also in the written one. In a study conducted by Kazazoglu (2020), first language negative interference was examined through the analysis of errors made by Turkish and Arab learners of English as a foreign language. The author analyzed 30 written assignments to detect grammatical and lexical errors. The results of the study showed that grammatical errors were more than lexical errors. As for learners' L1 interference, its role was clear in the spelling mistakes they made. The author stated that both groups learn English within the effect of their L1. However, the results also revealed that there were other causes of errors including using bilingual dictionaries, using direct translation methods and having poor language skills.

Furthermore, Ighzeel and Raha (2020) examined the negative influence of Arabic on the use of English passive voice of 46 Arab learners of English as a foreign language at the Universiti Malaysia Pahang. The results of the analysis showed that participants have a high rate of first language transfer in the use of English passive voice as the interlingual errors are more in number than the intralingual ones. Similarly, Al-Saidat and Warsi (2011) investigated the use of English article by Jordanian learners of English as a foreign language. The authors analysed 60 essays written by university students in order to find out the types and sources of errors committed in the use of the article. The results revealed that participants made substitution, omission and addition errors. As for the sources of errors, learners' first language played a significant role.

Kalaldeh (2016) investigated the English pronunciation of Jordanian students at the University of Jordan. She focused on errors committed in the pronunciation of English vowels, consonants, consonant clusters and word stress. The results revealed that the $/ \mathrm{p} /, / \mathrm{y} /, / \mathrm{x} /$ and $/ \mathrm{t} /$ were substituted by $/ \mathrm{b} /, / \mathrm{ng} / / \mathrm{s} /$ and $/ \mathrm{l} /$ respectively. It also indicated that there was a kind of confusion between the vowels /e/ $-/ \mathrm{I} /$ and /o:/ - /ov/. Moreover, participants inserted an epenthetic vowel in consonant clusters and used the primary word stress incorrectly.

Shalabi (2017) investigated the phonological awareness of the English dental fricatives $/ \theta$ / and $/ ð /$ among Chinese, Arab and Pakistani learners of English. The results of the study revealed that the English sounds $/ \theta /$ and $/ ð /$ were substituted by $/ ð /$ and $/ \mathrm{d} /$ respectively by most of the participants, especially the Pakistani and Chinese ones. The author concluded that these two sounds are problematic ones for the non-native speakers of English and their pronunciation is affected by learners' L1, age and level of education. Learners' L1 influence also was a cause of errors committed by Arab learners of English in a study conducted by Darweesh (2018) in addition to the teaching methods. The last factor, teaching methods, was also highlighted by 
Al-Sobhi and Preece (2018) as a factor that plays a role in the speaking skills of Arab learners of English.

Mashoor and bin Abdullah (2020) explored the English language of Jordanian secondary school students in terms of the structural errors they commit while speaking. Participants were Grade 10 and 11 students from public and private schools. The researchers conducted interviews with the participants in order to gather the required data. The result of the study showed that participants made errors of omission, addition, mis-formation and mis-ordering and their speaking ability was affected by shyness, lack of motivation and insufficient practice of English.

\section{Methodology}

This study aims to find out the difficulties that Jordanian learners of English encounter in the area of pronunciation being an important aspect that may hinder oral communication. To achieve this goal, the following research questions are posited:

RQ1. What are the types of phonological errors made by Jordanian learners of English?

RQ2. What are the reasons behind committing such errors?

RQ3. How to overcome learners' pronunciation difficulties in learning English in order to minimize the occurrence of errors?

To answer these questions, the researcher collected data from 20 Jordanian learners of English; all were in Grade 10 and speak Jordanian Arabic (JA) as their native language. The researcher asked each participant to read a list of word and recorded their pronunciation. These recordings constitute the data for this study.

\section{Analysis and Discussion}

The comparison of the phonological systems of learners' first language and their target language is necessary for several reasons. First, it makes the differences as well as the similarities between the two systems clear. Once these are clear, teachers may pay more attention to the differences being difficult areas for their students. Second, for researchers, it becomes easy to explain why certain target language sounds are easily acquired while others still are difficult. Finally, in error analysis studies such as the present study, knowing the differences allow researchers to predict the causes of the errors committed by their participants. In other words, researchers will be able to attribute learners' errors to first language interference.

As for the present study, Jordanian Arabic (JA, henceforth) is all participants' first language and English is the target language. However, Modern Standard Arabic (MSA, henceforth) might have a role to play since all participants have learnt it at their schools being the medium of teaching in Jordan.

Having looked at the inventory of the phonemes of the two languages, certain English consonants are not found in JA such as, / $\mathrm{p} /, / \mathrm{g} /, / \mathrm{v} / \mathrm{g} / \mathrm{J} / \mathrm{,} / \mathrm{z} /$ and $/ \mathrm{t} \int /$. Moreover, Arabic has only three short vowels, three long and two diphthongs, while in English there are seven short 
vowels, five long vowels and eight diphthongs. This results in that a number of English vowels are not found in the inventory of the JA phonemes including / e /, / p /, / ə /, / 3: /, / ə /, / əv /, / a /, / Iə /, / eə /, and / əə/, other English vowels, however, are used in JA either as phonemes or allophones of phonemes.

Another striking difference is found in the syllabic structure of the two languages. English allows up to three consonants in the onset and up to four in the coda, whereas JA allows two consonants in the onset and only one in the coda. Certain errors are predictable in this area.

As for this study, the participants made a number of phonological errors; some were made by inserting a sound that does not exist in the pronunciation of the word, while other errors were made by replacing the original sound with another one. However, participants' errors are classified into two major categories according to the process followed in their pronunciation: insertion errors and substitution errors.

\subsection{Insertion Errors}

In insertion errors, learners added a sound that does not exist in the pronunciation of the word either because they were misled by the English spelling in which some letters are silent or by the interference of the JA phonological system.

\subsubsection{The Influence of Spelling-to-Pronunciation Correspondence}

In Arabic, all letters of any word are pronounced. Having this habit internalized, native speakers of Arabic pronounce all the letters of any foreign word including the silent ones, especially the ones that are not always silent such as the letter ' $r$ ' in RP. In the data of this study, for example, the words 'first', 'hear', 'large', 'pleasure', 'shirt' and 'word' are pronounced as /ferrst/, /hr:r/, /la:rdz/, /blidzor/, / Jerrt/ and /wo:rd/, respectively. Another insertion is of the consonant $/ \mathrm{t} /$ as in /kæstrl/ 'castle'.

\subsubsection{Arabic Phonological Rules Influence}

As said earlier, in JA syllables are allowed to begin with an onset of one (C-) or two consonants (CC-), and to end in only one consonant in the code (-C), so when Arabic native speakers encounter an English word that begins with three consonants (CCC-) or ending in more than one consonant in the coda, they insert an anaptyctic vowel somewhere within such a cluster adding a new syllable to the word and therefore making it pronounceable for them, a process known as declusterisation. However, this true only for beginners; after some time, they adapt the phonological system of their new language and minimize the interference of their first language. The participants of this study inserted the short vowel/I/ in all the examples found in the data to erroneously ease the pronunciation of the difficult clusters in onsets and codas. See Table 1 below for examples of errors committed in this area.

Table 1. Vowel insertions

\begin{tabular}{|l|l|c|c|}
\hline & Error & $\begin{array}{c}\text { Correct } \\
\text { pronunciation }\end{array}$ & Spelling \\
\hline
\end{tabular}




\begin{tabular}{|c|c|c|c|}
\hline \multirow[t]{5}{*}{ Onset } & & & \\
\hline & /sıblæ// & /splæJ/ & splash \\
\hline & /sıblı:n/ & /spli:n/ & spleen \\
\hline & /sibrait/ & /sprait/ & sprite \\
\hline & $\begin{array}{l}\text { /sikri:n/ } \\
\text { /PIskri:n/ }\end{array}$ & /skri:n/ & screen \\
\hline \multicolumn{4}{|l|}{ Coda } \\
\hline & /a:skid/ & /a:skt/ & asked \\
\hline & / stubid / & / stppt / & stopped \\
\hline & / tikists / & / teksts / & texts \\
\hline & /kæstrl// & /ka:sl/ & castle \\
\hline
\end{tabular}

As clear from the above table, the word 'screen' has two erroneous pronunciations: /sikrı:n/ and /PIskri:n/. Both are attributed to the difficulty of pronouncing the cluster CCC-; the first one goes with the norm we established earlier, i.e., the insertion of $/ \mathrm{I} /$ inside the cluster and thus /skrı:n/ CCCVC became /sıkrı:n/ CVC-CVC, whereas the second involves a different technique which is the insertion of the Arabic glottal stop / $/$ and the short vowel at the beginning of the 'screen' turning it to a disyllabic word instead of a monosyllabic one. As a result, /skri:n/ CCCVC became / ?Iskri:n/ CVC-CCVC. The insertion of/ $/$ / at the beginning of the syllable can be attributed to the fact that JA does not allow syllables to begin with a vowel, so the structure $\mathrm{CV}$ - or CCV-seems to be obligatory in all cases. Other examples that show the insertion of $/ \mathrm{R} /$ at the beginning of words that have a vowel in their initial position include: / Povəla:nt f/ 'avalanche', / Pof/ 'of', / Pinglif/ 'English' and /?ind/ 'end'. Similar cases of declusterisation were reported in a study conducted by Sabbah (2015).

Furthermore, in the last example of coda insertions, the English 'castle' ends in a -CC coda, but because the learner had already erroneously inserted the consonant $/ t /$, discussed in section 4.1.1, it became -CCC making it more difficult to pronounce than earlier, a strong reason for the insertion of the anaptyctic vowel /I/.

\subsection{Substitution}

In substitution errors, learners unintentionally replace one sound with another sound producing a pronunciation error in the word in which the sound was replaced. As far as this study is concerned, the majority of errors fall under this category. The process of substitution seems to be governed by either that the target language sound does not exist in the JA phonemic inventory or the influence of spelling-to-pronunciation correspondence.

\subsubsection{Absence of the Target Language Sound from the Native Phonemic Inventory}

Because participants and Arab learners of English in general are not familiar with some of the English sounds, they replace them by other familiar ones. What is familiar to them here are the English sounds available in their native language. As for this study, participants substitute $/ \mathrm{b} /$ for $/ p /$ because the latter does not exist in JA, so /p/ changes into $/ b /(p>b)$ as in the examples: /gru:bz/ 'groups', /ba:rk/ 'park', /bin/ 'pen', /br:bul/ 'people', /bin/ 'pin',/bli:z/ 'please', /but/ 'pot', /bot/ 'put' and /sbin/ 'spin' (Kalaldeh (2016)). The substitution error in which p $>$ b results 
in some semantic errors in certain cases as the mispronounced word will have two meanings. For instance, /ba:rk/ will be understood as 'park' or 'bark' unless it is made clear from the context. Similarly, /bin/ 'pen' or 'bin'.

Another substitution error is $\mathrm{y}>\mathrm{ng}$ in which case wherever the combination 'ng' is found, it is pronounced $/ \mathrm{ng} /$ instead of $/ \mathrm{y} /$. This is because the sound $/ \mathrm{y} /$ does not exist in JA, so participants relied on the spelling of the words such as in /singər/ 'singer', /Pinglif/ 'English', /go:wing/ 'going' and /kılıng/ 'killing'. In addition, neither/t $\mathrm{J} /$ nor $/ \mathrm{z} /$ is available in JA, so t $\mathrm{s} \int$ as in / $\mathrm{fik} /$ 'chick' and / $\mathrm{I} \mathrm{ib} /$ 'chip', whereas $3>\mathrm{d} 3$ as in /disidzn/ 'decision'.

Due to the many differences between the vocalic systems of Arabic and English, many substitutions have taken place in the data of the present study. In short vowels substitutions, e $>\mathrm{I}$ is the most frequent in the available data. For example, /bin/ 'pen', /rid/ 'red'/tin/ 'ten' / $\mathrm{Ind} /$ 'end' and /klo:z frindz/ 'close friends'. As mentioned earlier, such errors may cause difficulties in understanding the intended meaning of the speaker. For instance, /bin/ may be understood as 'pen' or 'pin', /rid/ 'red' or 'rid' and /tin/ 'ten' or 'tin'. Another frequent substitution is $\mathrm{p}>\mho$; the English /p/ is substituted by / // as in /gut/ 'got', /?vf/ 'of', /but/ 'pot' and /stubrd/ 'stopped'.

Long vowels include long monophthongs and diphthongs. In monophthongs, /3:/ is the only vowel that seems to be a difficult area for the participants. It is replaced by /eI/ (3:>eI) as in / eerr/ / 'church', /ferrst/ 'first' and / eerrt/ 'shirt' or by /o:/ (3:>0:) as in /wo:rd/ 'word' and /wo:rk/ 'work'. While long monophthongs showed a single process of substitution for one sound, diphthongs seem to be more difficult for Arab learners of English because of the many differences between the systems of the two languages. According to the available data, three

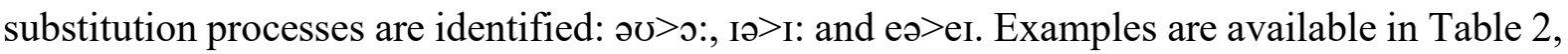
below.

Table 2. Diphthong's substitution processes

\begin{tabular}{|c|c|c|c|c|c|}
\hline \multicolumn{2}{|c|}{$\partial \sigma>0:$} & \multicolumn{2}{|c|}{$\mathrm{IO}>\mathrm{I}:$} & \multicolumn{2}{|c|}{ eə>eI } \\
\hline klo:z frindz & close friends & fi:rs & fierce & Serr & share \\
\hline go: & go & hI:r & hear & ðeIr & there \\
\hline ho:m & home & nI:r & near & & \\
\hline nə: & know & ji:r & year & & \\
\hline mo:st & most & & & & \\
\hline fo: & show & & & & \\
\hline
\end{tabular}

4.2.2 The Influence of Spelling-to-Pronunciation Correspondence

In Modern Standard Arabic (MSA), there is almost a one-to-one spelling-to-pronunciation correspondence, except for the ' 1 ' letter of the definite article which follows the pronunciation of the following sound in a number of cases. In other words, any written letter is pronounced, and its pronunciation is the same wherever it occurs. Being influenced by their first language, Arab learners of any foreign language, at least at the beginning stages, pronounce all the 
written letters of any word. Participants of this study are no exception. They substituted /ð/ for $/ \theta /$ in /mav $\theta d /$ 'mouthed' and /brr: $\theta$ Ing/ 'breathing' being influenced by the spelling 'th' which is pronounced $/ \theta /$ in 'mouth' and 'breath'. Moreover, the English past tense and past participle regular morphemes are pronounced /d/, /t/ or /Id/ but are orthographically represented by either 'd' or '-ed'; this creates a problem for beginners who have not acquired such a rule. Participants of the study seem to rely on the spelling and pronounced all the cases as $/ d /$, so $t>d$ as in /brodju:sd/ 'produced', /stobid/ 'stopped' and /a:skid/ 'asked'. Other instances of spelling influence include the pronunciation of 'these' as /ðı:s/ in which $\mathrm{z}>\mathrm{s}$ and /brı: $\theta / \quad$ for 'breath' in analogy with the vowel in 'read', 'meat', 'seat' and 'eat'.

\subsection{Right by Chance Errors}

As said earlier, Arabic has no $/ \mathrm{t} /$ sound; some of the participants replaced it by $/ \mathrm{J} /$ as in $/ \mathrm{Jk} /$ 'chick' and / $\mathrm{Ib} /$ 'chip', discussed in section 4.2.1 above. In the examples 'chef', 'machine' and

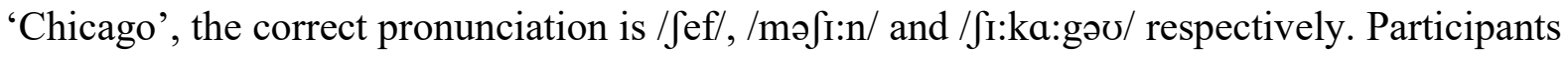
of this study pronounced them as $/ \mathrm{frf} /, / \mathrm{ma} \mathrm{I}: \mathrm{n} /$ and $/ \mathrm{fr}: \mathrm{kæg} \sigma /$ respectively in which $/ \mathrm{J} /$ is produced correctly. Normally, learners in their next stage will realize that there is an English sound $/ \mathrm{t} /$ / and words of this type will erroneously be produced with $/ \mathrm{t} / \mathrm{rather}$ than $/ \mathrm{J} /$, and when in an advanced stage they will acquire the correct pronunciation realizing that these words deviate from the regular pronunciation of the combination 'ch'. According to Corder (1981), utterances of this type are classified as 'right by chance' since learners have not reached the learning stage in which they learn that such sounds deviate from the norm. This can be applied to the participants of this study as well as they committed errors in the pronunciation of words having the sound $/ \mathrm{t} \mathrm{f}$.

\section{Conclusion}

This study investigates the phonological errors made by Jordanian learners of English in an attempt to explore the role of the first language in committing such errors. The analysis of the data revealed that participants relied heavily on their first language in the pronunciation of English words as clear from the examples discussed in the analysis section above. This is in line with findings of Al-Saidat and Warsi (2011), Darweesh (2018) and Ighzeel and Raha (2020). The participants either insert a sound that does not exist in the target language pronunciation (Al-Saidat, 2010) or substitute a sound for another. The process of insertion was motivated by what is there in their first language such as pronouncing all the letters of the word or declusterising an unfamiliar consonant cluster by inserting a short vowel in that cluster (Al-Shuaibi, 2006; Kalaldeh, 2016). On the other hand, the substitution process was caused either by the absence of the English sound from their native language phonemic inventory or the influence of spelling on pronunciation which they had already internalized while acquiring their first language.

Based on this, the study recommends that teachers of English as a foreign language are required to pay attention to the differences between Arabic and English, especially the phonological ones and provide a quite good amount of time for learners to have more practice on the difficult areas based on the comparison of the two phonological systems of Arabic and English. 


\section{Mll Macrothink}

Journal of Studies in Education

ISSN 2162-6952

2021, Vol. 11, No. 3

The findings of this are limited to Grade 10 group. Therefore, the results would be more generalizable if other groups were included. Further research on similar participants in different schools at different stages is needed in order to have a panoramic view of the various types and levels of errors in a way to help learners overcome these difficulties which will, in turn, improve their performance and ultimately academic achievements and their fluency in English being a global language. This study is hoped to contribute to the field of foreign language learning and teaching as it provides further knowledge regarding the types and sources of errors.

\section{References}

Abu Rass, R. (2015). Challenges face Arab students in writing well-developed paragraphs in English. Canadian Center of Science and Education, 49-59. https://doi.org/10.5539/elt.v8n10p49

Al-Saidat, E. (2010). Phonological analysis of English phonotactics: a case study of Arab learners of English. The Buckingham Journal of Language and Linguistics, 3, 121-134. https://doi.org/10.5750/bjll.v3i0.26

Al-Saidat, E., \& Warsi, M. (2011). Learners' use of article system: Jordanian students - a case study. Indian Journal of Applied Linguistics, 37(1), 71-81.

Al-Shuaibi, A. (2006). Phonological analysis of English phonotactics of syllable initial and final consonant clusters by Yemeni speakers of English. Unpublished MA thesis, Malaysia University Science, Penang State, Malaysia.

Al-Sobhi, B., \& Preece, A. (2018). Teaching English speaking skills to the Arab students in the Saudi school in Kuala Lumpur: problems and solutions. International Journal of Education and Literacy Studies, 1-11. https://doi.org/10.7575/aiac.ijels.v.6n.1p.1

Corder, S. (1981). Error analysis and interlanguage. Oxford University Press. London.

Darweesh, H. (2018). A qualitative study on problems in speaking English as L3: the case of Arab immigrants in Sweden. http://urn.kb.se/resolve?urn=urn:nbn:se:mdh:diva-42524

Ighzeel, F., \& Raha, N. (2020). The cross-linguistic influence of Arabic on the English passive voice. Global Journal of Foreign Language Teaching, 10(3), 182-190. https://doi.org/10.18844/gjflt.v10i3.4941

Kalaldeh, R. (2016). English pronunciation errors by Jordanian university students. Arab World English Journal (AWEJ), 7(2), 394-416. https://doi.org/10.24093/awej/vol7no2.27

Kazazoglu, S. (2020). The impact of L1 interference on foreign language writing: a contrastive analysis. Journal of Language and Linguistic Studies, 16(3), 1177-1188. https://doi.org/10.17263/jlls.803621

Mashoor, B., \& bin Abdullah, A. (2020). Error analysis of spoken English language among Jordanian secondary school students. International Journal of Education and Research, 8(5), 75-82. 


\section{Macrothink}

Journal of Studies in Education

ISSN 2162-6952

Richard, J. (1974). Error analysis: perspectives on second language acquisition. London: Longman.

Sabbah, S. (2015). Negative transfer: Arabic language interference to learning English. Arab World English Journal (AWEJ), 4, 269-288. https://doi.org/10.2139/ssrn.2844015

Shalabi, M. (2017). Think, tink or sink, the phonological awareness of English voiceless interdental fricative [ $\theta]$ and [ð] among Chinese, Arab, and Pakistani learners of English. American Journal of Education and Information Technology, 1(1), 8-14. http://sciencepg.com/journal/paperinfo?journalid=538\&doi=10.11648/j.ajeit.20170101.12 